\title{
TEKNOLOGI HIJAU: SOLUSI UNTUK PELESTARIAN SUMBER AIR
}

\author{
Nefilinda \\ Program Studi Pendidikan Geografi STKIP PGRI Sumatera Barat \\ nefilinda@yahoo.com
}

\begin{abstract}
This study aims to determine how these green technologies is a solution to preserve water resources. The research method is literature. The results obtained are: climate change caused by global warming are already being felt its impact in people's lives. If no preventive efforts, the impact of global warming in the future is a very serious threat to the lives of all the creatures on earth. In the face of the impact of Global Warming necessary mitigation efforts and adaptation that involves the community, such as water resource conservation technology with plant biology (bio-park), domestic waste water treatment technology with ecological sanitation (Ecosan), flower garden waste water (waste water garden), sanitation garden (sanita) and the concept of green technology (green tecnology). Green technology is one of adaptation and mitigation of the impact of Global Warming which is in line with the principle of sustainable development (sustainable development). Various Green Technology in the field of preservation of water resources and wastewater treatment has been available to be applied in the construction. Suggestions in this study are: for the government to attempt to campaign for the use of green technology and for the community also can use green technology in order to minimize global warming ranging from the household.

Keywords: green technology and conservation of water resources
\end{abstract}

\section{PENDAHULUAN}

Banyak penelitian mutakhir menunjukkan bahwa masalah pemanasan global yang terjadi saat ini disebabkan oleh perilaku manusia. Di era revolusi industri 50 tahun terahir ini penduduk dunia telah menggunakan sumber energi yang tak terpulihkan yang terlalu banyak dan telah merusak 50\% dari hutan dunia. Penggundulan hutan telah menghilangkan kemampuan untuk menyerap emisi karbon sehingga memacu terjadinya perubahan iklim. Sejak Perang Dunia II jumlah kenderaan bermotor di dunia bertambah sekitar 40 juta menjadi 680 juta, yang merupakan penyumbang emisi carbon dioksida pada atmosfer. Enam tindakan manusia yang dikenal sebagai "Tragedy of Commons" sebagai penyebab utama perubahan iklim global menurut Gany (2008) yaitu:

a. Meningkatnya kadar karbon dioksida (CO2) di atmosfir.

b. Perobahan terhadap siklus bio-kimia global dari nitrogen dan elemen-elemen lainnya.

c. pembentukan dan pelepasan komponen organik secara terus menerus seperti chlorofluorocarbon. 
d. Perubahan besar-besaran dalam tataguna lahan dan vegetasi tutupan permukaan.

e. Perburuan dan perambahan sejumlah besar sumber daya alam dan kehidupan predator dan konsumen.

f. Invasi keanekaragaman hayati oleh species asing.

Pada abad ke 21 ini, perubahan iklim yang diakibatkan oleh pemanasan global merupakan permasalahan yang serius dihadapi Negara-Negara di seluruh dunia. Intergovernmental Panel on Climate Change (IPCC) menyatakan bahwa kenaikan suhu bumi dari tahun 1990 - 2005 antara 0.13 - 0.15 derajat celcius. Apabila tidak ada upaya pencegahan, pada tahun 2050 - 2070 suhu Bumi akan naik sekitar 4,2 derajat Celcius, (KPKC Roma, 2002). Pada tahun 2100, suhu atmosfir akan meningkat 1,5 - 4,5 derajat Dampak pemanasan global yang akan terjadi adalah:

a. Musnahnya berbagai jenis keanekaragaman hayati.

b. Meningkatnya frekuensi dan intensitas hujan badai, angin topan, dan banjir.

c. Mencairnya es dan glasier di kutub.

d. Meningkatnya tanah kering yang potensial menjadi gurun karena kekeringan yang berkepanjangan.

e. Kenaikan permukaan laut hingga menyebabkan banjir yang luas. Pada tahun 2100 diperkirakan permukaan air laut naik hingga $15-95 \mathrm{~cm}$.

f. Kenaikan suhu air laut menyebabkan terjadinya pemutihan karang (coral bleaching) dan kerusakan terumbu karang di seluruh dunia.

g. Meningkatnya frekuensi kebakaran hutan.

h. Menyebarnya penyakit-penyakit tropis, seperti malaria ke daerah-daerah baru karena bertambahnya populasi serangga (nyamuk).

i. Daerah-daerah tertentu menjadi padat karena terjadinya arus pe-ngungsian.

Bagi masyarakat Indonesia dampak pemanasan global yang timbul antara lain kenaikan permukan air laut sampai $90 \mathrm{~cm}$ yang mengakibatkan tenggelamnya sekitar 2000 pulau, penurunan pH air laut dari 8,2 menjadi 7,8 yang akan menghambat kematian biota dan terumbu karang sehingga akan berdampak pada pertumbuhan ekonomi, yang mengakibatkan terjadinya penurunan populasi ikan 
dan sehingga menurunkan hasil laut seperti ikan, udang dan biota laut lainnya. Selanjutnya dampak ekonomi dan sosial akan terjadi akibat terendamnya sebagian besar kota-kota di wilayah pesisir. Dampak pada pertanian yaitu, akan terjadi menurunnya produktivitas tanaman karena terganggunya akibat perobahan pola presipitasi, penguapan, air limpasan dan kelembaban tanah. Selain itu pemanasan global juga berisiko terjadinya ledakan hama dan penyakit tanaman, sehingga akan menggangu pertahanan pangan. Peningkatan suhu Bumi akan menyebabkan curah hujan yang semakin lebat sehingga banjir akan lebih besar. Dampak pada kesehatan masyarakat akan meningkat karena peningkatan suhu akan memperpendek siklus hidup beberapa vektor penyakit dan masa inkubasi penularan menjadi lebih singkat terutama malaria dan Demam Berdarah, serta penyakit lainnya seperti Diare, Leptospirosis, kanker kulit, dll, (Kompas, 2007).

Banyaknya permasalahan yang disebabkan oleh pemanasan global, maka dirasa perlu untuk mencari solusi agar dapat meminimalisir dampak tersebut. Pleh sebab itu penulis merasa perlu membuat tulisan ini, yang berjudul, "Penerapan teknologi hijau merupakan solusi untuk melestarikan sumberdaya air”.

\section{METODOLOGI PENELITIAN}

Penelitian ini merupakan studi pustaka, karena penelitian ini diambil dari beberapa sumber atau penelitian yang telah di terbitkan oleh peneliti sebelumnya.

\section{PEMBAHASAN}

\section{Teknologi pelestarian sumber air}

Dengan menggunakan Taman Biologi (Bio-Park). Bio-Park merupakan salah satu teknologi hijau yang digunakan untuk memperbaiki kualitas sumbersumber air yang tercemar seperti air saluran, sungai dan danau. Proses reduksi bahan-bahan pencemar dalam Bio-Park terjadi melalui siklus rantai makanan dalam ekosistem akuatik atau ekoteknologi. Di Jepang, teknologi Bio-Park diterapkan untuk memperbaiki kualitas air danau antara lain Danau Tsuchiura, Kibagata, Koishikawa, dan Haruno.

Teknologi Bio-Park juga telah dimodifikasi sebagai taman atap (Roof Top Bio-Park) di perumahan Canon Housing . 


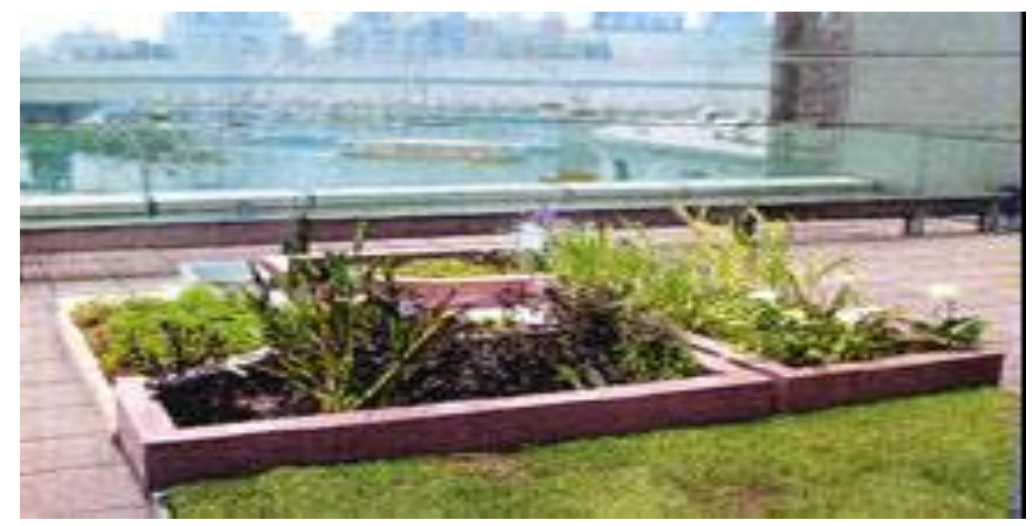

Gambar 1. Rooftop Bio-Park di Perumahan Canon Jepang Sumber: Top Ecology, Co, Lt

Pada saat ini teknologi Roof Top Bio-Park dikembangkan dalam rangka mitigasi pemanasan global yang terjadi di daerah perkotaan. Dalam 5 tahun terahir, teknologi Bio- Park telah diperkenalkan ke Thailand, China dan Brazil melalui bantuan teknik pemeritah Jepang. Karena menggunakan proses ekosistem alami, teknologi Bio-Park merupakan upaya adaptasi dan mitigasi dampak pemanasan global dengan karakteristik sbb:

a. Menanam vegetasi

b. Memperbaiki kualitas air yang tercemar secara efisien tanpa bahan kimia.

c. Memanfaatkan lumpur sebagai pupuk organic

d. Tidak menghasilkan limbah kimiawi

e. Bio-Park adalah "zero emission System"

Teknologi Bio-Park mendapat penghargaan dari WHO pada tahun 1997 sebagai teknologi masa depan pengendalian pencemaran danau. Pada tahun 2002, Bio_park memenangkan peringkat terbaik pada "Environmental Contest" di Jepang. Pada tahun 1998, Bio-Park telah terdaftar hak paten dengan merk dagang BIO-PARK dan nama :Hydrophonic Biofilter System. Hak paten dipegang oleh Top Ecology.Co.Ltd.

Di Indonesia, percobaan lapangan penerapan teknologi hijau untuk pelestarian kualitas air danau telah dimulai oleh Pusat Litbang Sumber Daya Air pada tahun 2003 di Waduk Saguling dengan nama EKOTEKNOLOGI. Penelitian masih berlangsung sampai saat ini dan diharapkan teknologi ini dapat dipersiapkan untuk diterapkan oleh pemeritah dan masyarakat. 


\section{Teknologi Pengolahan Air Limbah Domestik}

\section{a. Ecological Sanitation}

Ecological sanitation (Ecosan), merupakan teknologi hijau yang diharapkan menjadi revolusi baru untuk peningkatan kesehatan masyarakat melalui upaya pengolahan limbah domestik. Ecosan didasarkan kepada tiga prinsip yaitu:

1) Pencegahan pencemaran lebih baik daripada melakukan pengendalian dan pengawasan setelah terjadi pencemaran.

2) Perbaikan sanitasi tinja dan urine

3) Pemanfaatan produk Ecosan untuk pertanian

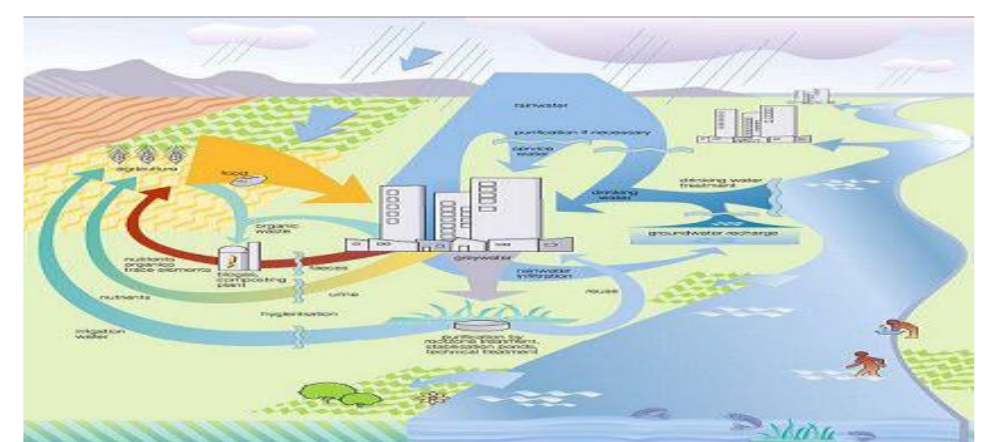

Gambar 2. Prinsip Pengolahan Limbah Domestik dengan Ecosan

\section{Sumber: GTZ}

Pada saat ini $40 \%$ penduduk dunia tidak memiliki sarana sanitasi yang memadai. Sekitar satu milyar penduduk dunia terutama anak-anak terinfeksi parasit dan mengalami kekurangan gizi serta hambatan dalam pertumbuhannya, dan sekitar 6000 anak meninggal setiap harinya karena penyakit perut yang disebabkan buruknya kondisi sanitasi, data dari (Winblad, 2004). Di Indonesia sebanyak 19,7\% dari total penduduk belum memiliki jamban. Fasilitas sanitasi dengan sistem perpipaan (sewerage system) baru dibangun di tujuh kota, dengan cakupan pelayanan total 5,57\%. Jumlah rumah tangga yang memiliki fasilitas sanitasi dengan menggunakan tangki septik baru mencapai sekitar $40 \%$. Pelayanan fasillitas air minum melalui sistem perpipaan baru mencapai $44,4 \%$ di perkotaan dan hanya 9,4\% di pedesaan, data dari (Cipta Karya, 2008). 
Menurut laporan Bank Dunia, Indonesia termasuk salah satu Negara yang memiliki tingkat pelayanan sanitasi terendah di Asia. Sebagai akibatnya wabah penyakit yang ditularkan melalui air terjadi secara rutin, dan insiden penyakit tipus di Indonesia, merupakan yang tertinggi di Asia. Kerugian ekonomis yang diakibatkan oleh isu ini, secara konservatif diperkirakan US\$ 4,7 milyar per tahun, atau 2\% dari GDP, yang setara dengan US\$ 12 per rumah tangga per bulan, data dari (World Bank, 2003). Pada saat ini banyak tempat di dunia yang kekurangan air dan dalam 50 tahun terahir ini penggunaan air dunia meningkat tiga kali lipat. Diperkirakan pada tahun 2030 separuh dari penduduk dunia akan kekurangan air.

Pembuangan limbah, yang berasal dari Instalasi Pengolah Limbah (IPAL) baik yang terpusat maupun yang setempat (on-site) merupakan penyebab utama pencemaran sumber-sumber air yang belum dapat diatasi. Selain mencemari sumber air permukaan limpasan dan bocoran zat pencemar tersebut juga mencemari air tanah.

Penerapan teknologi Ecosan diharapkan dapat mengatasi tantangan yang belum dapat ditanggulangi pada bidang sanitasi terutama dalam mengatasi masalah sanitasi saat ini dan menghadapi perkembangan penduduk dunia dimasa yang akan datang. Keunggulan Ecosan dalam upaya mitigasi dan adaptasi pemanasan global adalah:

a. System daur ulang tertutup (closed loop) yang sempurna dalam siklus rantai makanan manusia sehingga seluruh buangan dimanfaatkan kembali tanpa ada sisa limbah yang terbuang.

b. Menghemat penggunaan air dan pembuangan air dalam siklus hidup manusia

c. Mencegah pencemaran lingkungan dan konservasi potensi kualitas sumber-sumber air.

d. Mengembalikan unsur hara tanah, memperbaiki stuktur tanah per-tanian dan mengurangi penggunaan bahan kimia sebagai pupuk. 
e. Mencegah terjadinya penyakit yang ditularkan melalui air (waterborne desease)

f. Sederhana dan murah sehingga memungkinkan untuk dilaksanakan seluruh lapisan masyarakat

\section{b. Taman Buangan Air Limbah (Wastewater Garden)}

Wastewater Garden (WWG) adalah teknologi hijau yang digunakan untuk mendaur ulang sisa zat pencemar dari unit pengolahan limbah perumahan, hotel, restoran, atau perkantoran. WWG merupakan $100 \%$ ekologis, murah dan mudah dalam pembangunan, pengoperasian dan pemeliharaannya. Tanpa memerlukan peralatan mekanis dan bahan kimia, air limbah di daur ulang secara gravitasi ke taman, kebun sayuran, ataupun buah-buahan. WWG pada awalnya dikembangkan untuk melindungi pantai dari pencemaran limbah penduduk.

Kontribusi penerapan teknologi WWG dalam mitigasi dan adaptasi dampak pemanasan global karena:

a. menanam vegetasi

b. meningkatkan kualitas effluent ke lingkungan tanpa bahan kimia dan peralatan mekanis

c. Ekologis, mudah dan murah

Teknologi WWG dikembangkan oleh Planetary Reef Foundation dan telah berhasil diterapkan di Meksiko, Bali, Bahama, Belize, Perancis, Polandia, Pilpina, Amerika Serikat dan Australia. WWG yang terbesar saat ini adalah Xpu-Ha EcoPark di Meksiko yang dirancang untuk mengolah limbah 1500 pengunjung per hari. Di Indonesia, teknologi WWG telah di uji coba pada beberapa kantor pemerintah daerah dan diterapkan pada beberapa hotel di kawasan Nusa Dua.

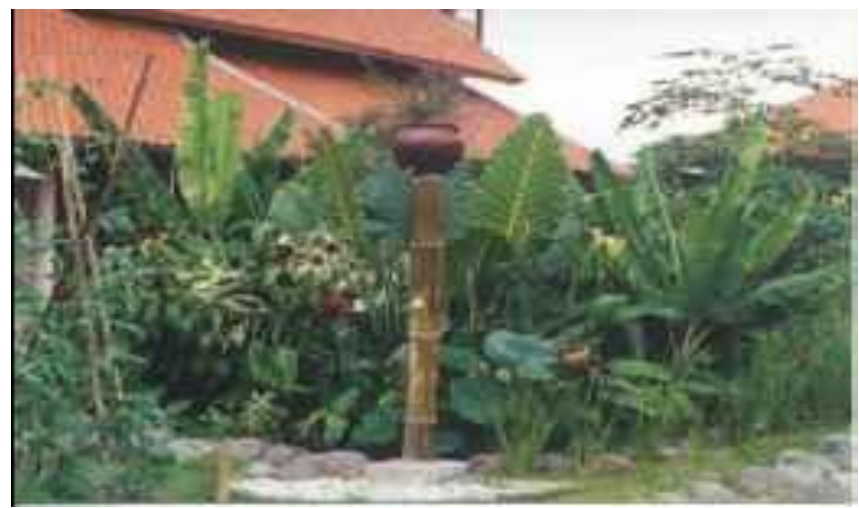




\section{Gambar 3. Wastewater Garden di Bali Sumber: Planetary Reef Foundation}

\section{c). Sanitasi Taman (SANITA)}

Sanitasi Taman (SANITA), adalah Teknologi Hijau untuk memperbaiki kualitas effluent tangki septik konvensional agar tidak mencemari air tanah. Effluen septik tank konvensional masih mengandung bakteri Fecal Coli yang cukup tinggi dan beresiko mencemari air sumur dangkal yag terletak berdekatan, terutama pada permukiman yang padat. Sebagian besar penduduk perkotaan masih mengkonsumsi air tanah dangkal sebagai sumber air minum dan rumah tangga sehingga mereka berisiko tinggi terjangkit penyakit perut (waterborne deseases). SANITA mampu menurunkan

bakteri Fecal Coli pada effluent tangki septik sampai dengan lebih dari $99 \%$ sehingga diharapkan tidak mencemari air tanah. Penerapan SANITA pada permukiman akan menambah vegetasi permukaan yang merupakan salah satu upaya adaptasi dan mitigasi dampak perobahan iklim. Selain itu SANITA juga

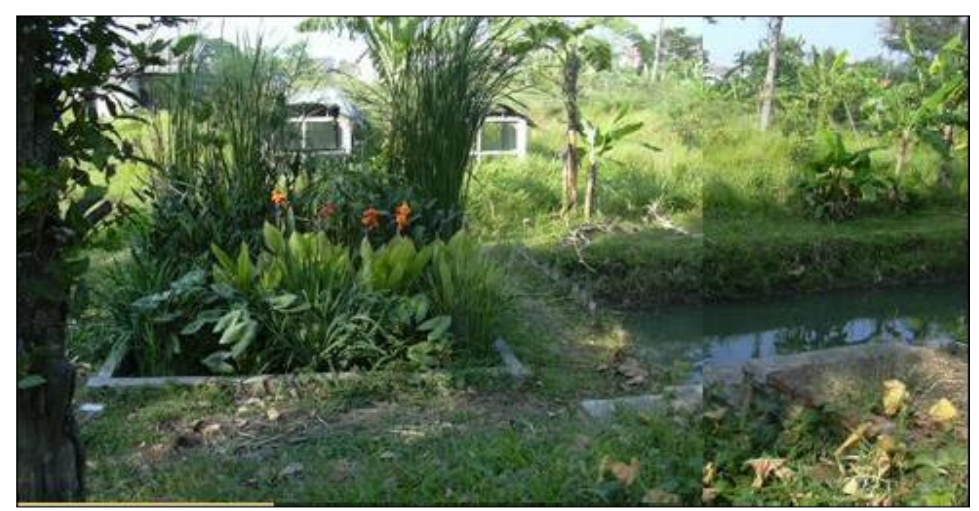

mudah dan murah dalam pembangunan, pengoperasian dan pemeliharaannya, serta tidak menggunakan bahan kimia dan peralatan mekanis. SANITA telah diteliti oleh Pusat Litbang Permukiman sejak tahun 2004 dan saat ini telah disusun pedoman tata cara pembangunannya sebagai kelengkapan Standar Nasional Indonesia tentang Tata Cara Pembangunan Tangki Septik.

\section{d) Konsep Teknologi Hijau (Green Technology)}

Green Technology (Teknologi Hijau), diartikan sebagai suatu ilmu pengetahuan praktis / teknologi yang dapat digunakan untuk melaksanakan pembangunan yang dapat mewujudkan tatanan infrastuktur untuk memenuhi kebutuhan manusia secara berkelanjutan (sustainable development), tanpa merusak 
atau mengganggu sumber daya alam. Secara singkat, teknologi yang dapat digunakan untuk memenuhi kebutuhan generasi saat ini dan tidak mengganggu ketersediaan kebutuhan generasi mendatang, dari (Green Tecnology, 2008)

Keberadaan teknologi hijau ini diharapkan dapat menjadi inovasi bagi manusia untuk merobah gaya hidupnya seperti kegandrungan manusia saat ini akan information technology (IT). Beberapa ciri Teknologi Hijau antara lain: berkelanjutan (sustainable), menggunakan sumber alam yang terbarui (reclaimed), menghasilkan produk yang bermanfaat kembali (re-used), mengurangi produk limbah dan bahan pencemar, menggunakan proses terdaur ulang (recycle), inovatif tidak berbahaya bagi kesehatan dan lingkungan, menciptakan kegiatan dan produk yang ber-manfaat bagi lingkungan atau dapat melindungi bumi.

\section{KESIMPULAN}

Perubahan Iklim yang diakibatkan oleh Pemanasan Global telah dirasakan dampaknya dalam kehidupan manusia. Apabila tidak dilakukan upaya pencegahan, dampak pemanasan global di masa yang akan datang merupakan ancaman yang sangat serius bagi kehidupan semua makhluk di bumi. Dalam menghadapi dampak Pemanasan Global diperlukan upaya-upaya mitigasi dan adaptasi yang melibatkan masyarakat, seperti teknologi pelestarian sumber air dengan tanaman biologi (biopark), teknologi pengolahan air limbah domestik dengan ecological sanitation (Ecosan), taman bunga air limbah (waste water garden), sanitasi taman (sanita) dan konsep teknologi hijau (green tecnology). Teknologi Hijau merupakan salah satu upaya adaptasi dan mitigasi dampak Pemanasan Global yang sejalan dengan prinsip pembangunan yang berkelanjutan (sustainable development). Berbagai Teknologi Hijau di bidang pelestarian sumber air dan pengolahan air limbah telah tersedia untuk diterapkan dalam pembangunan.

\section{DAFTAR PUSTAKA}

Bellwood DR, Hoey AS and Choat J.H., 2003. Limited functional redundancy in high diversity

Buddemeier RW, Kleypas JA and Aronson R., 2004. Coral Reefs and Global Climate Change:CCSP (Climate Change Science Program and the Subcommittee on Global Change Research), 2003. 
Gany, A.H.A, 2008, Implikasi Multi Dimensional Perubahan Iklim Global Menyongsong Pengelolaan Sumber Daya Air Terpadu, makalah kunci pada Kolokium Hasil-Hasil Litbang Sumber Daya Air, Bandung 23 -24 Juli 2008. Geochemical consequences of increased atmospheric carbon dioxide on coral reefs. Science

Green Technology, 2008, Strategy and Leadership for Clean and Sustainable Communities, http:// www.green-technology.org

Harian Kompas, 01.12.2007, Dampak Pemanasan Global Bagi Negara Kita, Jakarta.

Harvell CD, Mitchell CE,Ward JR, Altizer S, Dobson AP, Ostfeld RS and Samuel M.D., 2002.

Kadarsah (2007). http://kadarsah.wordpress.com/2007/11/30/mengenal-iklimindonesia/; Kelompok Kerja Pemanasan Global, 2002, Pemanasan Global dan Perubahan Iklim, Promotor KPKC, Jakarta.

Planetary Coral Reef Foundation, 2008, Wastewater Garden, Potential Contributions of Climate Change to Stresses on Coral Reef Ecosystems. Prepared for Pusat Litbang Sumber Daya Air. 2003. Penelitian dan Pengembangan Ekoteknologi untuk Pelestarian Sumber-sumber Air" Bandung: Badan Litbang Depertemen Pekerjaan Umum

Queensland Greenhouse Taskforce. Department of Natural Resources and Mining,Townsville, Rosen B and Roughgarden J., 2003. Climate Change, Human Impacts, and the Resilience of Salm, R.V. and S.L. Coles (eds). 2001. Coral Bleaching and Marine Protected Areas. Proceedings of Science Program,Washington DC systems: resilience and ecosystem function on coral reefs. Ecology Letters 6:281-285.

The Workshop on Mitigating Coral Bleaching Impact Through MPA Design, Bishop Museum, Top Ecology, 2008, Product and Service Bio-Park (internet). Vision for the Program and Highlights of the Scientific Strategic Plan, US Climate Change 
Water and Sanitation Program-East Asia and the Pacific (WSP-EAP), 2007, Economic Impacts of sanitation in South East Asia Summary, World Bank East Asia and the Pacific Region. western Indian Ocean 63:353-372.

Western Indian Ocean. Estuarine, Coastal and Shelf Science: Science for management in the Winblad U and Hebert M.S, 2004, Ecological Sanitation, Stockholm Environment Institute, Stockholm, Swedia 